\title{
Hybrid space as a conceptual framework for adaptation
}

\author{
Eman Al Braifkani* \\ Kağan Günçe** (1)
}

\begin{abstract}
Adaptive reuse is a common formula for reliving life in spaces that are no longer used for their original function, whether through physical adjustments or by incorporating virtual environments into space to Create hybrid spaces with a new dimension in which the data of memory, culture and space identity interact. Although the trends of the studies vary in their approach to deal with the concept of adapting architectural spaces, they remain in the same theme that the process of space adaptation is seen to be based on either one or the other, Oblivious to the fact that the process of building adaptation generates tension and creates hybrid spaces which belong to neither. Thus, the studies that focused on this subject does not reach the creation of a clear and specific theoretical framework for adapting architecture to changing cultural and social requirements and desires. This research attempts to examine the possibility of investing the concept of hybrid to consider different dimensions of architectural adaptation. The relevance of hybridity theory to understanding architectural adaptation is a subject that has hardly been explored. An objective of this research is to investigate this research gap represented of absence of specialized studies help to understand the relationship between the concept of hybrid and architectural adaptation and lack of the proposed concepts that accommodate new patterns of adaptation to preserve more than one characteristic (perhaps in conflict) within the original space. In light of this, the research problem is represented in the absence of a clear and comprehensive theoretical framework that enables the identification of forms of adaptation that respond to changing cultural and social requirements and desires. Hence, this research seeks to combine Bhabha's concept of hybrids and adaptation of architecture to build a clear and comprehensive perception of this concept, by using architectural studies that dealt with these subjects.
\end{abstract}

Keywords: adaptation, adaptive reuse, culture, hybrid space, hybridity.

\section{Introduction}

The discussion of space returns back to a Greek philosophy and has been seen in significant changes over time. It is transferred from being an abstract, standalone image to a physical image where then a relationship between things take shape by people organizing their relationships with each other and with their environment (Casey, 1997, Schulz, 1971, Bartel, 2014, Heidegger, 1996, 
Dyson, 1998, Al-Juboori \& Mustafa, 2014). Today, there have been several studies confirming the mutual influence of space, society and culture (Lefebvre, 1991). As Soja points out, that most of our lived spaces are socially constructed indicating that humans have an impact on other human beings and the ways in which our cities and social spaces are constructed, can have a big impact on our daily lives. Thus, space became" reflective mirror of societal modernization." (Jagannath, 2018). The different languages, customs, traditions and the way of how people react to their environment represent a manifestation of cultural diversity based on the presence of more than one influential group "Diversity is nothing more than a difference from the majority" (Lee, 2018) that expresses its identity. This diversity affects people and how they shape cognitive maps, which in turn are used to influence the behaviour of the individual within the same environment or in similar environments (Haq and Griotto, 2003). Thus, the identities of people that can be determined by difference from the other more than the similarities as Huyssen indicates (Huyssen, 1995) can lead to identify hybrid spaces, it corresponds to a cultural diversity that creates hybrid images and drives the need for a building adapted to these requirements rather than denied them. Than here, architecture buildings, cities, spaces - can be conceived according to Bhabha, as a subject in the "hybrid space", that area where culture is at its most productive, because buildings (and cities) are always metaphorically in the middle between architects' interests, developers' economic expectations and planning laws, while also being continually re-signified by users (Hernández, 2010). For this reason, the question is raised about how and under what conditions the processes of Building adaptations occur in a manner that aligns with the concept of hybrid space as an image of the cultural diversity and cultural difference that associated with modern design methods and practices.

Homi Bhabha, an Indian English scholar and critical theorist and can be consider as one of the most highly renowned figures in contemporary post-colonial studies (Huddart D, 2018). His idea of hybridity suggests an approach to reading adaptations that accommodate these stimuluses. In the context of this study, it questions what form does hybridity take in architecture, what is a 'hybrid' space and how might one identify it? The relevance of hybridity theory to understanding architectural adaptation is a subject that has hardly been explored. An objective of this research is to investigate this research gap. In order to give a more solid understanding of hybrid, the research focuses on a number of research topics that accompanied the adaptation of architecture to the requirements and desires of contemporary societies and builds links between them, including the hybrid space generated by the combination of public and private spaces, and the hybrid place that allows for multiple layers of users and use across time, and the overlap between cyberspace and physical space. The research adopts the qualitative approach in its study due to its compatibility with the nature of the subject under study. Qualitative research tends to emphasize a holistic exploration of complex situations and environments where testing and deduction of sequenced or causal relations are unlikely. Creswell notes that qualitative research usually aims to "involves reporting multiple perspectives, identifying the many factors involved in a situation, and generally sketching the larger picture that emerges" (Creswell, 2007). Depending on the analysis of architectural studies that dealt with these vocabularies, in addition to studying a number of contemporary adaptation projects (as part of the qualitative research Tactics (Miles \& Huberman, 1994), this leads to a finding of a solid interpretation of the adaptation processes in light of the concept of hybridity. Qualitative research typically aims "to develop a complex picture" that "involves reporting multiple perspectives, identifying the many factors involved in a situation, and generally sketching the larger picture that emerges" (Creswell, 2007).

\section{Adaptation in Architectural Studies}

The concept of adaptation has led to widespread interest in different science, such as sociology and biology. It was also the focus of a wide range of architectural studies due to its relevance for the theoretical field and the practical reality of the architecture. It has acquired different meanings depending on the trend of each study, yet we can classify these trends into three categories: The first category covered topics such as extending the life cycle of the building (Kohler and Hassler, 
2002) and the possibility of adaptive reuse unoccupied buildings (Douglas, 2006). Over time buildings are exposed to the possibility of losing their original functions for various reasons which required a number of modifications to ensure that the building can used to achieve the new purpose, (ICOMOS, 2013) Adaptation begins with changing the function or using building to respond changes in the economic influences such as (market situation, low value of the building and exploitation it economically) or by social effects such as (user desires to leave building due to bad condition, renewal, and changing the usage type). This will following by a physical adjustment of the building to suit the changing function (Kincaid, 2002). This category of studies has been focused on the concept of adaptation as Modifications to the building in response to a variety of motives, it's about overcoming aging and redundancy in buildings, and to ensure the long-term future of buildings threatened with demolition and vacancy at the end (Douglas, 2006).

The second category of studies dealt with the concept of "adaptation" in relation to the flexibility. Where it refers to the ability to adapt the environment with changing needs of the occupants in a timely manner however these modifications become possible if the original design of the building has flexibility enough to adapt a new requirement (Douglas, 2006), meaning the possibility of providing a state of laxity between the events and spaces to accommodate the changes that can occur over time without any need to modify the building. This happens either by providing spaces more than the requirements of the events at the time of occupancy called (Over Capacity) or by providing spaces with general or similar characteristics that can be used by different events called (Neutrality) (Al-Nijaidi, 1985).This property is known as flexibility and is described by Hillier "as the ability of a complex to accommodate functions in general and therefore potentially a range of different functions, rather than any specific function" (Hillier, 2007). This category pointed out the benefits of adaptation to the environment and the reduction of pollution and its contribution to environmental sustainability through flexibility and Thoughtful design (Kincaid, 2002). While, the third Category of studies deal with modifications to an architectural type to suit the natural, civilizational and semantic environment, As with changes in the Bungalow type in India at the level of the plans and structure of the building (Photo 1, Photo 2), along with decorations, ornaments and changes to the type of the residences on Penang Island in Malaysia (Desai, M., Miki D and Jon L., 2011, Abel, 1997).
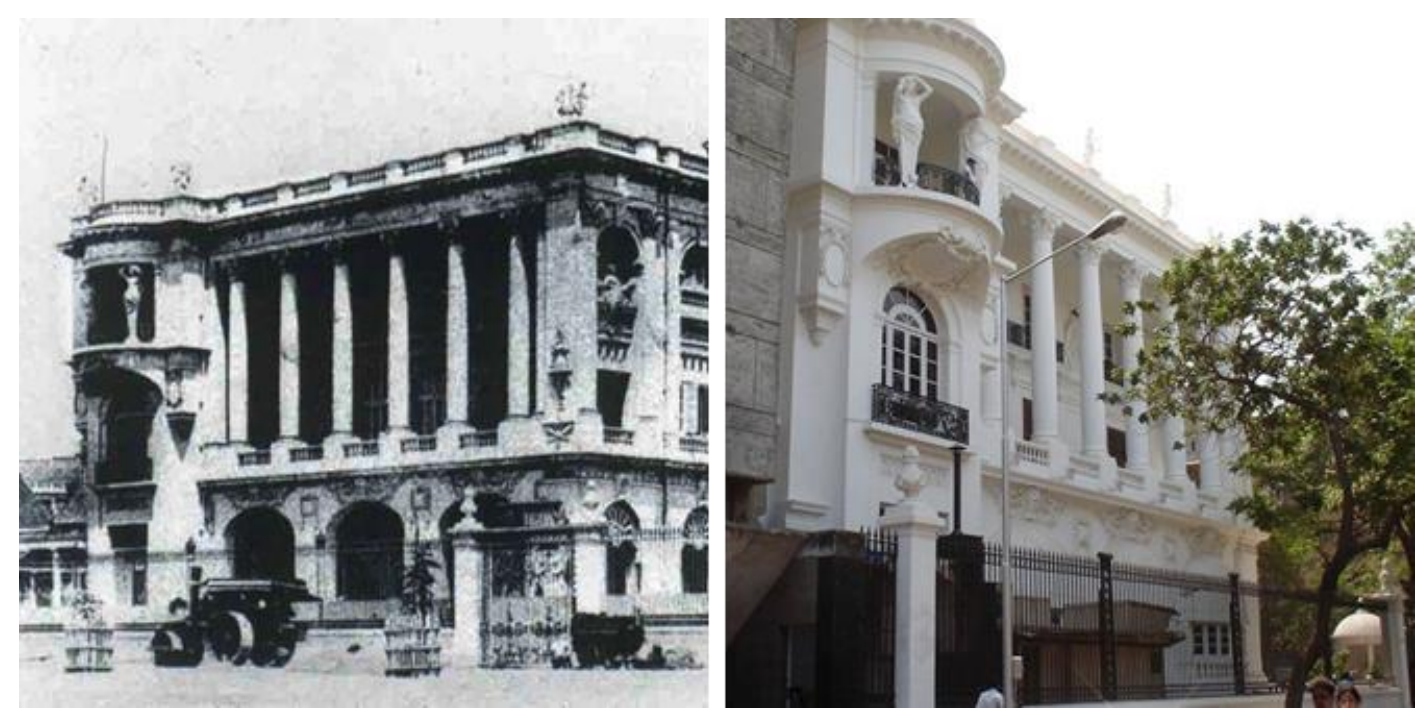

Photo 1 The erstwhile Tata Palace in Mumbai is now the corporate headquarters of Deutsche Bank. This building exemplifies an adaptation of Using of Baroque Embellishment with indigenous Indian architecture. (Desai, M., Miki D and Jon L., 2011) 


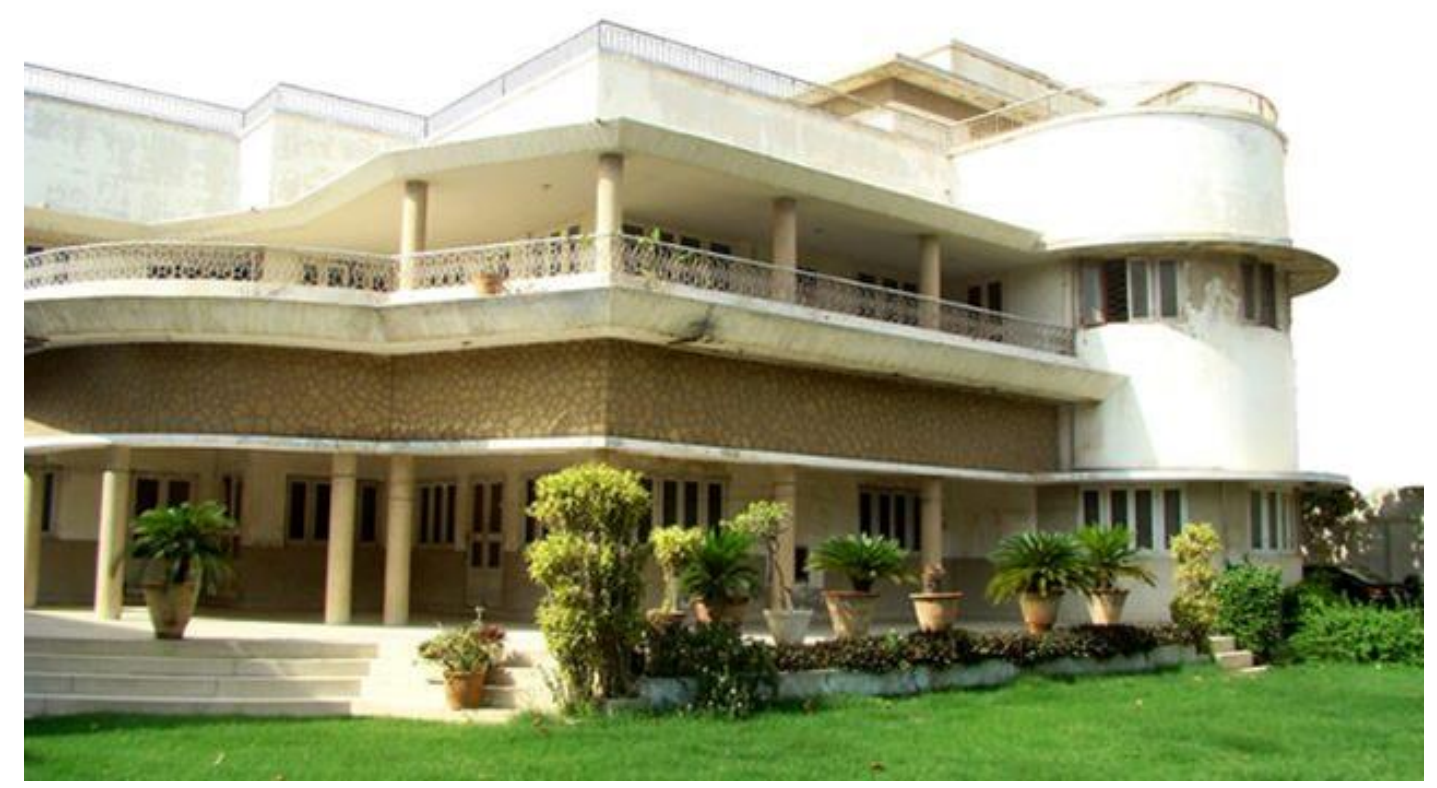

Photo 2 An Art Deco building off Shahrah-e-Faisal in Karachi (Desai, M., Miki D and Jon L, 2011)

Although the trends of the studies vary in their approach to deal with the concept of adapting architectural spaces, they remain in the same theme that the process of space adaptation is seen to be based on either one or the other. Oblivious to the fact that the process of building adaptation generates tension and creates hybrid spaces do not belong to either, contrary to the goal of adaptation by owning the building and transferring it to new culture, separated on both allowing for continuity and discontinuity at the same time (Alsayyad, 2001). This paper claims that, at present architecture adaptation and their space head to generate hybrid space impelled by the need to address different requirements, desires and provide multifunctional spaces. As noted in recent years, multifunctional buildings adaptation has been increased where spaces become more complex than their predecessors and it can be observed that the interaction of separate functions has been strengthened, and the internal boundaries of space begin to dissolve.

\section{Hybridity and Adaptation}

\section{Homi Bhabha and Richard Sennett claims:}

The word "hybridity" has its origins in biology and botany where it designates a crossing between two species by cross-pollination that gives birth to a third "hybrid" species. While Darwin praised the fertility of the process of cross-pollination, others pointed to the risk of degeneration when the term was applied to the field of genetics and racial interbreeding (Guignery, 2011). The historical context of the "hybrid", had a negative concept, while today the concept is everywhere, however today it has begun to take widespread acceptance on the cultural and global levels. Due to technology grow, many hybrid areas appear, Hybrid cars, hybrid plants, and hybrid materials which become increasingly common terms in today's world. In the twentieth century, the term hybrid extended beyond the biological and racial framework to embrace linguistic and cultural areas.

The concept of hybrid returns to its understanding the difference between "cultural diversity" and "cultural difference", according to Bhabha. The first refers to the possibility of different cultures coexisting side by side in one space without being influenced or be affected, while "cultural 
difference" refers to a form of declaration of cultural diversity that may lead to non-coexistence within space if interaction does not occur on the basis of showing hegemony. This leads to create the concept of hybrid space as a compound space trying to adapt to maintain more than one property (possibly in conflict) of the original space, allowing the overlap of two cultures or two different concepts that maintain a kind of interaction (Bhabha, 2006). Today's world imposes us to adapt on the basis of: Create complexity and interconnectedness in a city tends to differ rather than change, A city where people withdraw behind walls of difference. Contemporary world adds Sennett, pushed toward overlapping different activities in the same area. For instance, Create a family activity in the workspace. This brings us back to the issue that had characterized the appearance of the industrial city itself. A city that shattered the pre-emergence spatial relationship Industrial capitalism combines family, work and ceremonial public spaces and more informal spaces.

Consideration of adaptation through the concept of hybrid space is consistent with the nature of the era in which people appear more flexible in the way they move and, in the way, they adapt to the new environment. The common use of spaces and presence with strangers can have a positive effect "about the sociability of living with strangers: the mark of the civic realm now is mutual accommodation through dissociation. That means the truce of letting one another alone, the peace of mutual indifference." (Sennett, 2008) and here Richard Sennett points out that "There are more and more people who feel the urge to live the life of a nomad, who would live anywhere in the world and who could hardly remember where they lived just ten years ago." (Sennett, 2008)

A hybrid space is often understood as a location for exploring issues of dominance, power and emancipation. It is a means to imagine new ways of working, new ways of talking and original, transformative ways of relating (Loveday, 2008). the term hybrid refers to an interaction of two unlike genes resulting in a new breed that is different and unique in nature (Sargın G, Savas A, 2011). Technically, speaking, the product of zoological hybridization is often a sterile animal, but the term is often used metaphorically to designate creativity, the creation of new specimens (Guignery, 2011). From this standpoint, it could find new understanding of the subject of building adaptation based on the combination of contradictions in one space without one being dominant over the other.

\section{Hybrid Adaptation}

The concept of hybrid space allows an understanding of adaptation in positive terms. Like an accordion instrument, it is able to adapt easily to accommodate the constant change that accompanies the cultural diversity and difference which is a feature of contemporary societies as well as changing concepts related to attachment to place. Where Hybridity becomes one of the ways to Re-adaptation of buildings. Hybridity broadens the field of innovation, not by making them available through traditional boundaries- These boundaries can be physical or cultural and are places, real or imagined-only, but by defining boundaries as a hybrid, flexible, and multi-layered space, not just a place to merge differences, but as a place for transformation and innovation. From this vision, it could be stand on by three aspects of tension that form a conceptual framework for hybrid space as an adaptation of contemporary buildings

\section{Public-Private access:}

Hybrid concept has become more and more frequent at internal and external spaces where the border between public and private began to fade in favor of hybrid spaces do not belong to either. For example, most people are convinced that Railways are considered as public spaces, but today it can be found that many of these stations have been integrated into arrival and departure areas 
with the spaces of various shopping centers under private ownership and retail stores under the same roof (Nissen, 2008) thus, the public space is divided into private properties. This redefines modern railways stations as a hybrid space (neither public nor private) . This conviction that people have spaces such as transport stations and heritage or historical buildings are based on their memory of the stereotype of this type of space which allows continuity and discontinuity at the same time.

Moreover, the proliferation of imaging and broadcasting techniques has contributed to bringing public space to private and vice versa, create new spaces between the two spaces. While today, changes the concept of privacy have influenced the way of understanding identity. Separation between interior and exterior or between public and private is no longer clearly evident. People live as Bhabha pointed out in between (hybrid) area: 'the zone of occult instability where the people dwell' (Bhabha, 1994) where public space is brought to private and virtual space to reality with preservation the properties of each one. In reality television shows such as (Big Brothers) a model of hybrid spaces, Where the public access into the house and family's private rooms through TV cameras, in sharp contrast to the "privy chamber" concept which first appeared in the bourgeois era and accompanied English literature in the 17th century to denote private place and place of soul (Private Identity) (Lukacs, 1970).

In the project for "Room 202 at the Gladstone Hotel", which designed by, Maggie Greyson, and Christine Lieu, identifying the Public-Private access by adapting one rooms of the hotel to be an area where quests exchange personal memories, each person shares a piece that represents his memory, which is placed in a transparent glass box with a comment explaining what it represents (or what it symbolizes) and another piece that represents the memory of another person is taken in exchange for it, but without meeting them. "The playful take on memories and storytelling was arranged like a simple library with long shelves of rough planks mounted from floor to ceiling lined with mason jars each housing an object and an identifying tag. In this case, semi-anonymous objectstory-memories are the focus of the art, but in a very ephemeral way. They become commodities with exchange value, and they float in and out of the archive, like they would in the mind of a person or community" (Photo 3) (“Undertaking Acquisition," n.d.).

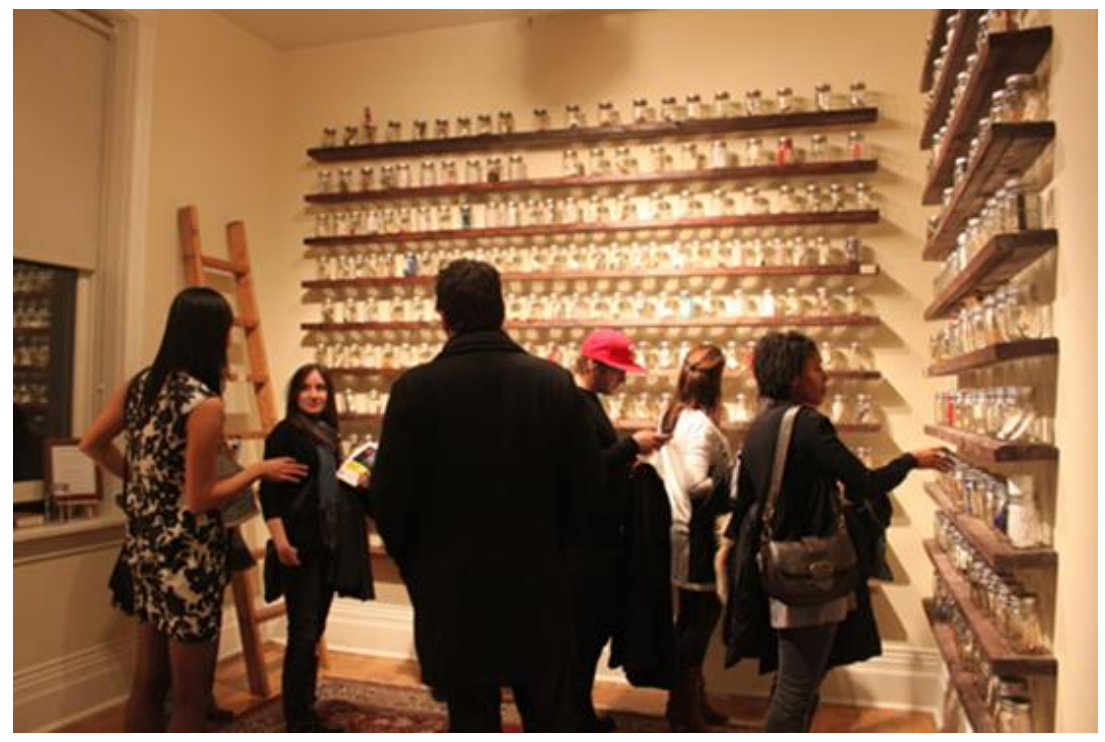

Photo 3 Room 202 at the Gladstone Hotel (“Undertaking Acquisition” n.d.)

The concept of hybrid space based on the combination of antipodes of public space and private space becomes a fundamental concept in buildings with overlapping functions, in office buildings, 
for instance, as a result of changing the work culture based on the individual towards team-based work it could be notice that reduction in the individual area in favor of creating an unallocated space that provides the possibility of daily change. And the XYZ Works building in Manchester, which opened in 2017, goes a step further by providing hybrid workspaces and spaces (open work space) shared by more than one companies that operates in the city's tech, technology and digital (FinTech) communities in one open space (Photo 4) ("XYZ Works, Manchester's newest hybrid cowork space to launch in August - Invest in Manchester," n.d.).

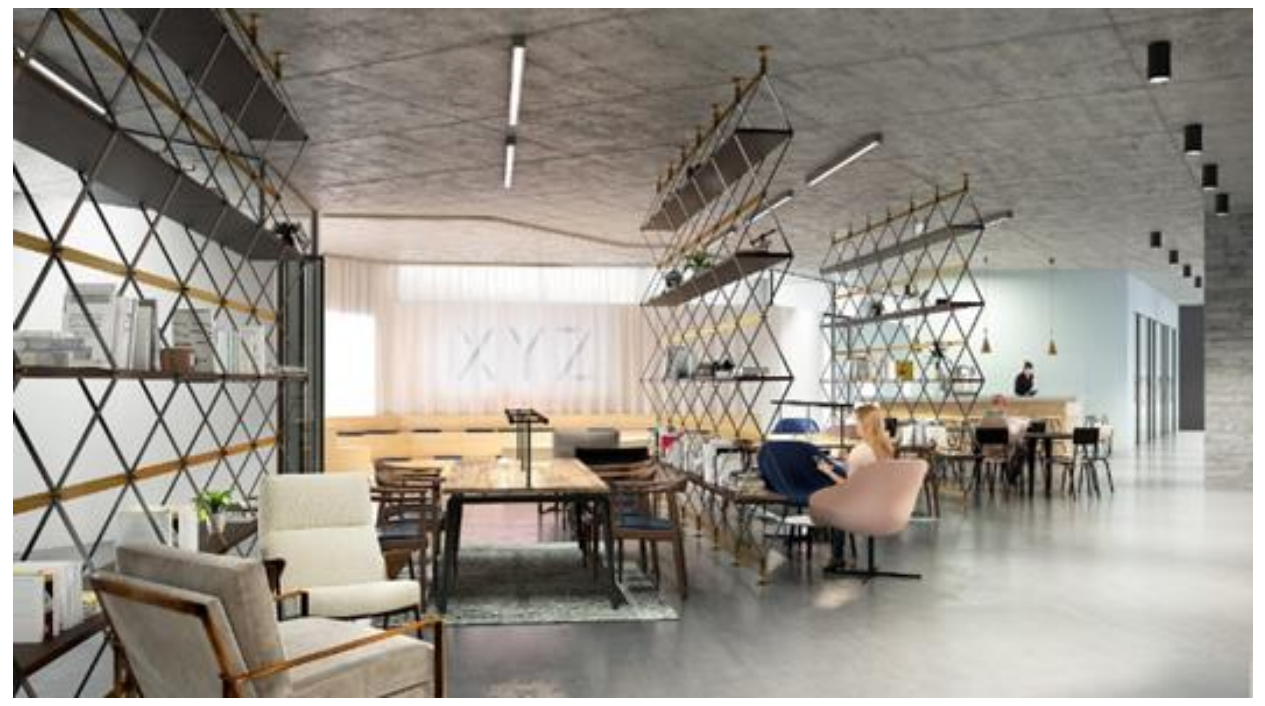

Photo 4 "XYZ Works is set to define a new era in co-working spaces in Manchester. Opening in August 2017, XYZ Works represents the evolution of flexible work spaces to the next level and has been specifically designed to cater for FinTech, digital, professional service and tech-enabled businesses in the landmark XYZ Building at the heart of Spinning fields." (“XYZ Works, Manchester's newest hybrid co-workspace to launch in August - Invest in Manchester" n.d.)

On the other hand, there is another attraction of public spaces towards private spaces, monitoring cameras surrounds public spaces and turns it into a space for the municipality. And residential spaces with fences and gates that are guarded by security men and are limited to a certain group of people, carves out public space, roads and parks to redefine it as a public but fenced "hybrid". What is thought to be a public park (public space) is actually a different space today, the garden is fenced and closed at specific hours. Even its furniture is made of materials that cannot be slept on with metal cushions, and its public bathrooms are open only during the day. Thus, these "hybrid" spaces receive the desired people and exclude others (Nissen, 2008). The principle of "unlimited access" And the principle of "usability" in the sense that it can be used by the general public without restrictions in the light of its specific function (Low \& Smith, 2006), the definition of public space, have been displacement in favor of a hybrid space reflecting a profound cultural shift that replaces stereotypes with a flexible identity based on difference and interconnection, where this type of adaptive is required. Thus, a new aspect of building adaptation has emerged through a hybrid perspective based on a combination of the two space (public and private) under one roof, allowing them to be present and continue to play their roles without allowing those two overtake each the other.

\section{Hybrid - Adaptive Reuse:}

Today's architectural spaces offer multiple models of hybrid spaces that can be found everywhere around us, industrial areas transformed into new cultural landscapes, cemeteries used as public parks, places of various events and activities with temporary installations or light structures, vertical gardens, interchanges and transportation hubs, pedestrian passages, large scale urban sculptures, experimentally revitalized historical spaces, public spaces combined with hybrid 
buildings (Pluta, 2016). Due to relatively long age of the building, it is possible to undergo partially or totally changes in the function, form or use, which adds a new layer of memories and meanings of the building. This paradox, or multiplicity of fossils, allows to generate new concepts and meanings as well as to recognize existing fossils, which give the new class special importance (Peterson \& Rutherford, 2006). Thus, created hybrid space that holds the characteristics of past and present at the same time and place and allows continuity and interruption in the cultural environment. Memory and images of the past are constantly evolving; it is woven through the dialectic of remembering and forgetting, it exists to choose what suits them and focus on it whether it is space, building or gesture (Nora, 1989). In the Museum of Glass and Ceramic For the architecture Hollien in Theran, brings an ancient palace to life in a complex and rich way in Ambivalent meanings. It is considered one of the examples in which a building is adapted, allowing memories to coexisting side by side permitting multiple reading generated sensory meanings. Hollien, uses large display boxes (or black columns) each generates a completely different psychological state against a background of Rococo plaster (Jencks, 1993) (Photo 5). The building is a hybrid space presenting ancient art in post-modern containers within different historical contexts under one roof.
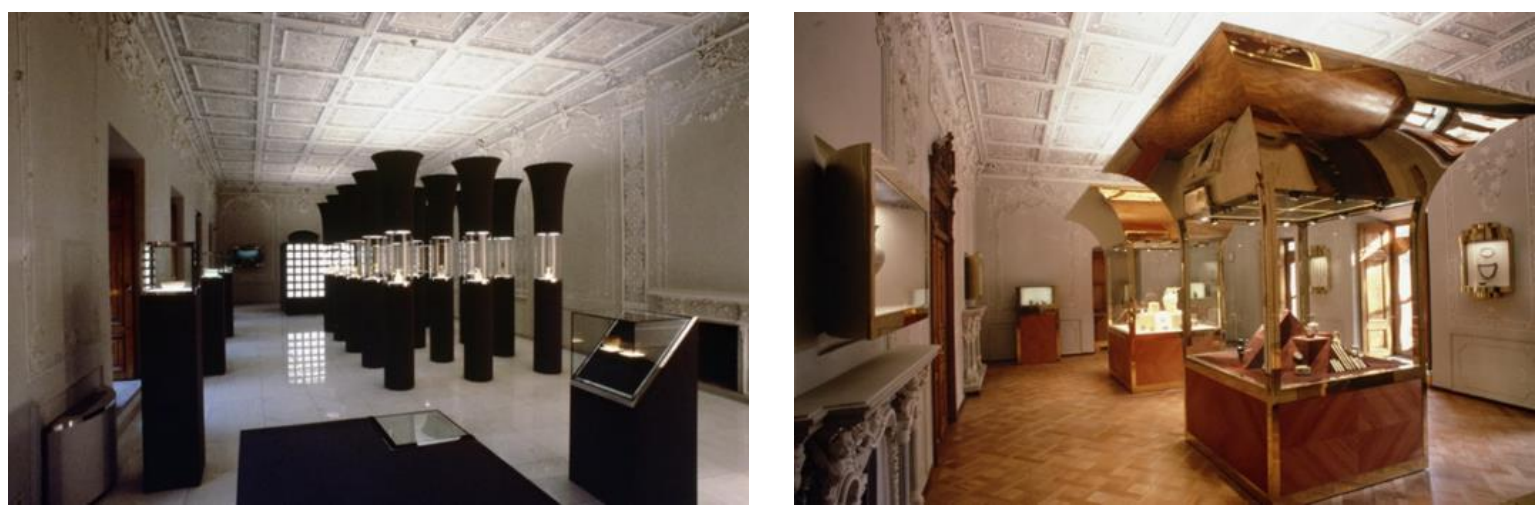

Photo 5 The Museum of Glass and Ceramic in Theran. (Jencks, 1993)

The building which houses Glassware and Ceramic Museum of Iran was built 90 years ago upon the order of Ahmad Qavam (Qavam-ol-Saltaneh), the premier of Qajar King Ahmad Shah as a personal lodging (residence-cum-office) "Later, the building was sold to the Egyptians as the new location for the Egyptian Embassy and remained in their possession for seven years. When relations between Iran and Egypt were severed during the rule of Gamal Abdul Nasser, the Egyptian Embassy in Tehran was closed and the building was purchased by the then Commercial Bank. However, it was sold in 1976 and turned into a museum jointly by Iranian, Austrian and French architects. The museum was opened in 1980 and was registered on the National Heritage List in 1998 The architectural style of the building is a combination of Iranian style and European architecture of the 19th century (Jencks, 1993).

Another manifestation of the building's adaptation to "changing needs through reuse based on the accessibility of the space and its elements by multiple people at different times throughout the day and night, form different types of memories. In 2009 Zecc Architects is adapting the old Droste Silo to a hybrid space with Changeable identity by day and night. The Droste chocolate factory in Haarlem is an icon of industrial architecture in Haarlem. The complex, founded in 1897 along the Spaarne waterway. During the Second World War a bombing by an Allied aircraft, caused considerable damage to parts of the Droste site. The old factory is abandoned in 2004 and reconverted into housing in 2006. This old Building transformed by Zecc Architects to a hybrid space 
with Changeable identity by day and night for "Studio Heldergroen". Their ground floor studio "Studio Heldergroen" in the old Droste Silo looks like a smart, modern office by day. But within a matter of seconds, the space can be transformed into a yoga studio, a communal eating area, a DJ set and a dancefloor (Steeds, 2014). Every evening the tables and the computers disappear in the white acoustic ceiling landscape with Led lighting. Only the chairs on the black concrete floor reminds of a hard-working day". ("Studio heldergroen | Zecc Architecten," n.d), (Photo 6, Photo 7). Throughout the day, the building is combined with different interest users. In the morning, the building is known as offices, and by the evening the building is known as a dance floor. Thus, a hybrid space is formed that carries in its fossil layers the industrial building next to the office building whose employees do their work in the city square.

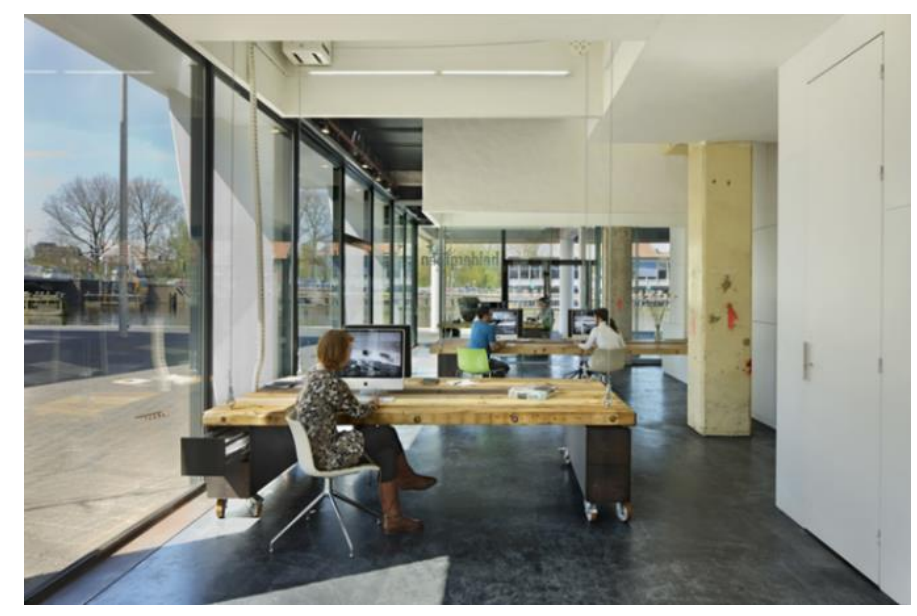

Photo 6 The ground floor studio "Studio Heldergroen" in the old Droste Silo, modern office by day. ("Studio heldergroen | Zecc Architecten" n.d)

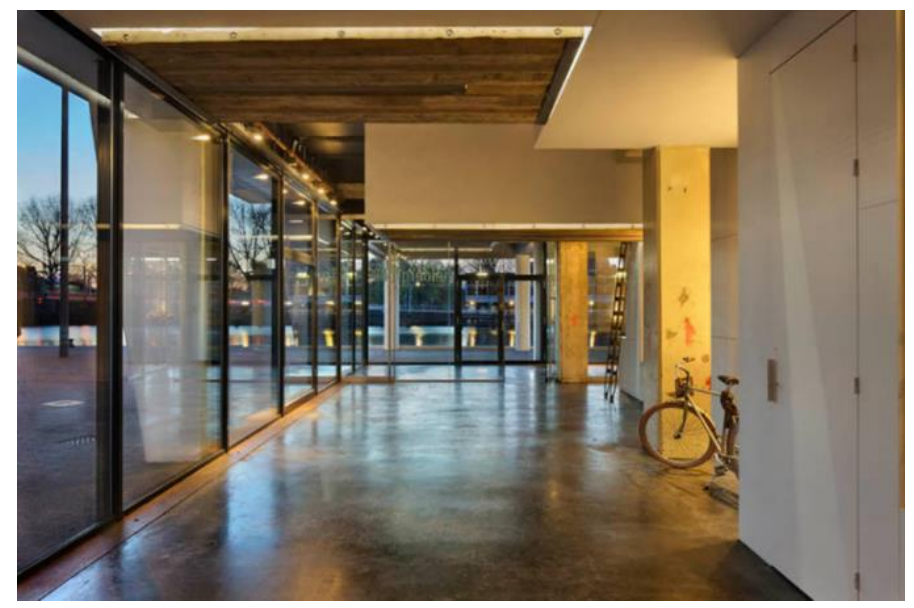

Photo 7 The ground floor studio Studio Heldergroen in the old Droste Silo, can be transformed into a yoga studio by night. ("Studio heldergroen | Zecc Architecten" n.d)

In this context, buildings and their spaces will be part of the network of relationships woven into memory over time and will contribute greatly to building memory. As buildings that extend for a relatively long period of time with their environment, it linked to this environment with a very complex network of relationships. Which gives this relation a stronger link to the environment compared to other elements (Dalton \& Bafna, 2003) and memory formation, becomes a confirmation of meaning than to be as material stabilizations of past times (Guggenheim, 2009). The multiplicity of communication patterns through the integration of historical spaces into 
contemporary solutions and the change of function over time, creates new features of space adaption from hybrid perspective based on expressive identity, providing flexibility at both the functional and design levels and providing a kind of cohesion that allows users to perform stationary and variable activities.

\section{Adaptation with Flowing Spaces:}

Following Lebebvre's theory with the understanding of space as a combination of different 'fields' - physical space, mental space, and social space, Cicognani (1996) adds that cyberspace can be considered as the 'fourth partition' of space that is in co-existence with the other 'fields. (Chan, 2010). Cyberspace can be viewed as a real space rather than a mere thing where communities interact, grow and evolve within it (Cicognani, 1996). New communities are created within Cyberspace - such as social spaces which described according to Lefebvre-Located outside the traditional spatial coordinates. With mobile devices, the private is drawn into public spaces through communications and with augmented reality feature it accumulates layers of information about the surrounding environment which affects our choices and behavior. These spaces become aa a place of consciousness, characterizes by constant change and movement and allows people to move between its worlds continuously, which is reflected in the people's attachment to a space. It is also comparable to Lefebvre's mental space; both of them represent the reality we live in. Mental space representation of the outside world can be accessed through the individual whose image resides in the mind; while cyberspace space can be envisioned though it disappears between networks online through screens (Dyson, 1998).

Today, in the light of Information and communications technology (ICT) a new space is being created that has a radical impact on the way in which people interact with each other in their societies and in how they shape and define space. Castells refers to the invasion of mass media and networks of our physical environments. Where these spaces enter architectural spaces in competitive relationships and sometimes as interactive frameworks (Castells, 1996). Where the latter becomes (architecture and its space) as a reference points used by people as starting points guiding himself to explore the surrounding environment and to build his perception of the spaces and the connection between spaces (Schulz, 1971). A. Scarponi, S. Massa, F. Pedrini, A. De Luca, in their project called "Dreaming Wall" in Italy, present a representation of a hybrid space that combines the digital world and the information network with the physical space (Photo 8). Where the multiplicity of events successively released each other-as day released night and the attachment of space becomes as a transient event. "The Dreaming Wall is a project for a blank wall in an historical square of Milan, originally submitted for a competition. The wall is conceived as an Info Forum: a public vertical space reflecting the dual character of the city which has a double life as the city and the piazza do - white and subdued during the day and glowing phosphorescent green at night." The project presents a new picture of the adaptation of an old building with the changing of the city and cultural of contemporary society, as the wall is seen as "The Wall is seen as a tool of cultural, simultaneous, and random collective communication, creating a visual buzz. As a public digital billboard, the wall surface at night randomly displays text messages sent by people standing on the square or from anywhere else in the world through the Internet. The messages are generated in real time by a chemical reaction between a computer-controlled UV laser projection and phosphorescent panels on the wall. This release the text provoked by the UV light, which is actually invisible. A message would last fifteen minutes before being re-absorbed by the wall. Its constant transience metaphorically suggests the sub consciousness of a city asleep." ("The Dreaming Wall. Collective Buzz in Town. - Conceptual Devices" n.d). 

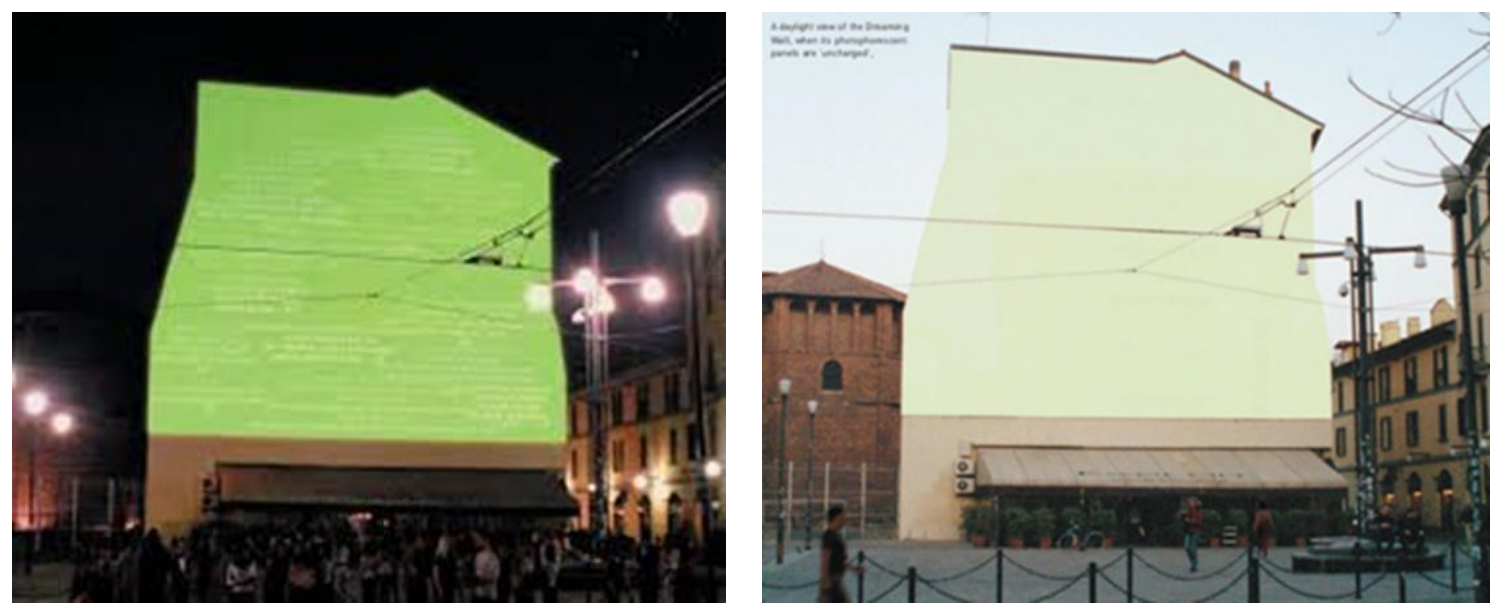

Photo 8 "Dreaming Wall" in Italy (“Conceptual Devices" n.d)

In MOCA occupies a former machine shop, Maya Lin a Chinese-American architect provides her experience integrating media with a building. She provides an experience of a hybrid space that integrating media with a the "Museum of Chinese in America" space. In an interior loosely inspired by a traditional Chinese house, with rooms radiating off a central courtyard and areas defined by screens, the images flicker on monitors set into the crumbling red brick, "MOCA's core exhibit traces the development of Chinese communities on these shores from the 17th century to the present through objects, images and video. Maps on the floor connect to a further history in objects suspended from above. More often, though, the museum relies on images and text, including light boxes set into the walls. A mocked-up Chinese general store evokes the multipurpose spaces that served as vital community lifelines for men severed from their families under the 1882 Exclusion Act, which restricted immigration" (Photo 9) (E.B. Boyd,2009, Ridhika Naidoo, 2009).
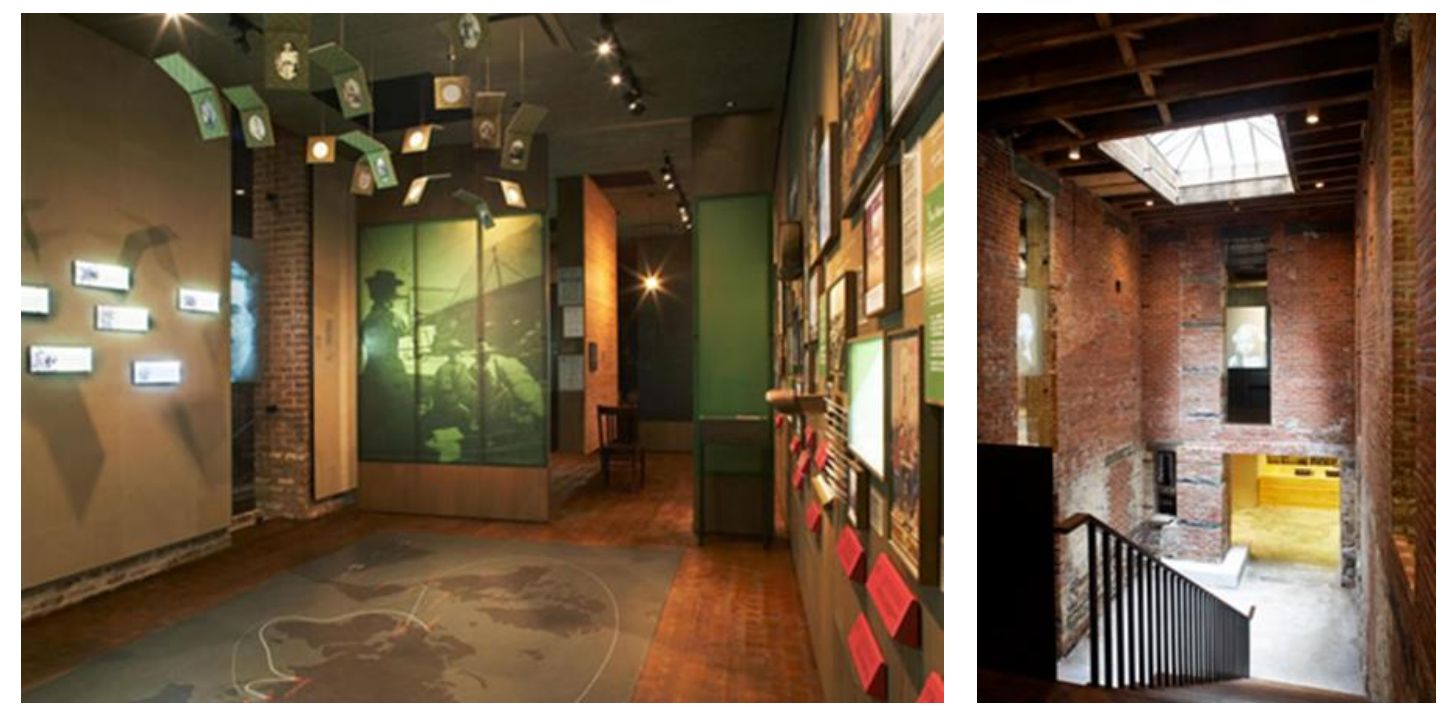

Photo 9 Museum of Chinese in America, 2009, Maya Lin (E.B. Boyd, 2009, Ridhika Naidoo, 2009)

This combination of digital telecommunications network and architectural space generates a third space that can be described as "Hybrid Space" based on a building adaptation aspect allowing architectural space flowing within Cyberspace space and vice versa without obstruct each other in the form of continuous succession and existence at the same time.

In light of the above, Table 1 shows that in addition to the formulas that mentioned previously, the new formulas of adaptation can be identified in the light of the concept" hybrid", which appears 
as a result of the response of architecture and its spaces to various requirements and desires. Building adaptations have become more complex than their predecessors, along with the interaction between different functions, and the blurring of internal boundaries of spaces.

Table 1 Different formulas of building adaptation from the perspective of hybrid space

\begin{tabular}{|c|c|c|}
\hline Formulas & Literature review & New formulas(author) \\
\hline $\begin{array}{l}\text { Relation to changing function: This will be } \\
\text { following by a physical adjustment of the building } \\
\text { to suit the changing function }\end{array}$ & $\begin{array}{l}\text { (Kohler and Hassler, 2002) } \\
\text { (Douglas, 2002) }\end{array}$ & \\
\hline $\begin{array}{l}\text { Relation to the flexibility: by providing spaces } \\
\text { more than the requirements of the events at the } \\
\text { time of occupancy or by providing spaces with } \\
\text { general or similar characteristics that can be used } \\
\text { by different events }\end{array}$ & $\begin{array}{l}\text { (Al-Nijaidi, 1985), } \\
\text { (Kincaid, 2002), } \\
\text { (Hillier, 2007) }\end{array}$ & \\
\hline $\begin{array}{l}\text { Relation to the architectural type: As with } \\
\text { changes in the level of the plans and structure of } \\
\text { the building, decorations, and ornaments. }\end{array}$ & $\begin{array}{l}\text { (Desai, M., Miki D and Jon L, 2011), } \\
\text { (Abel, 1997). }\end{array}$ & \\
\hline Public-Private access & & $\begin{array}{l}\text { Bringing public space to private and } \\
\text { vice versa, without allowing those } \\
\text { two overtake each the other }\end{array}$ \\
\hline Hybrid -Adaptive Reuse & & $\begin{array}{l}\text { Multiple layers of users and their } \\
\text { change over date and time }\end{array}$ \\
\hline Adaptation with Flowing Spaces & & $\begin{array}{l}\text { allowing architectural space } \\
\text { flowing within Cyberspace space } \\
\text { and vice versa without obstruct } \\
\text { each other in the form of } \\
\text { continuous succession }\end{array}$ \\
\hline
\end{tabular}

\section{Conclusions}

The current paper dealt with building adaptation from the perspective of hybrid space in the contemporary buildings and took different formulas, concluding that dealing with building adaptation from hybrid perspective can create new understanding of the relationship between architecture and society accepting diversity and difference as a manifestation of life Which is accompanied with people change their attachment to space, where people live in places that are constantly changing. In hybrid spaces, people tend to accept the participation with strangers in different ways and within diverse spaces and architecture must provide its interpretation of the economic, political and cultural conditions that accompany the growth of cities through their walls and spaces.

Building adaptation from a hybrid perspective does not attend to be as a single course to generating space, and respond to contradictions and expectations required but as an activity allows to preserve the preservation of developments (bringing public space to private and vice versa, Multiple layers of users and their change over date and time and Living between flowing spaces Architectural spaces) critically involved with issues of contemporary requirements such as nonattachment of space, emancipation, non-personalized and property topics. 


\section{References}

Al-Juboori, U. A., \& Mustafa, F. A. (2014). Assessing the efficiency of functional performance of shopping malls in the Kingdom of Bahrain. International Transaction Journal of Engineering, Management, and Applied Sciences and Technologies, 5(3), 143-165.

Al-Nijaidi, H, R. (1985). Flexibility in the Design of Buildings (Doctoral dissertation, Oxford Polytechnic).

Alsayyad, N. (2001). Hybrid Urbanism, Identity Discourse and the Built Environment, Praeger, London

Bartel, Marvin, (2014) "Elements and Principles of Design". IncredibleArt.org. Retrieved 1 Dec. 2018.

Bhabha H. 1994. The Location of Culture. London, UK: Routledge

Bhabha, H.K. (2006). Cultural Diversity and Cultural Differences. in The Post-Colonial Studies Reader, B. Ashcroft et al (eds). Routledge: New York: $155-157$.

Casey, E. S. (1997). How to get from space to place in a fairly short stretch of time: phenomenological prolegomena. In S. Feld, \& K. H. Basso, Senses of place (pp. 13-52). Santa Fe: School of American Research Press.

Castells, Manuel. (1996). The Rise of the Network Society. Massachusetts: Blackwell Publishers.

Chan Thomas. (2010). Rethinking space + place: negotiating a social realm between mobile technology and architecture. Master of Architecture.

Cicognani, A. (1996). On the linguistic nature of cyberspace and virtual communities. Virtual reality, 3(1), 1624. Retrieved October 27, 2009, from: http://fragment.nl/mirror/various/Cicognani_1996.html

Creswell. (2007). Qualitative Inquiry \& Research Design: Choosing among Five Approaches (Thousand Oaks, CA: SAGE, 2007).

Desai, M., Miki D and Jon L. (2011). "The Bungalow in Twentieth Century India: The Cultural Expression of Changing Ways of Life and Aspirations in the Domestic Architecture of Colonial and Post-Colonial Society", Ashgate, UK. All photographs are by Miki Desai.

Douglas, J. (2006). Building Adaptation (2nd edition), London: Elsevier.

Dyson, F. (1998). "Space," "being," and other: fictions in the domain of the virtual. In J. Beckmann, The virtual dimension: architecture, representation, and crash culture (pp. 26-45). New York: Princeton Architectural Press.

E.B. Boyd (2009). Telling the story of Chinese-Americans. Retrieved December 24, 2020, from: https://paw.princeton.edu/article/telling-story-chinese-americans

Guggenheim, M. (2009). Building memory: Architecture, networks and users. Memory Studies, 2(1), 39-53.

Guignery V. (2011). Introduction: hybridity, why it still matters hybridity: forms and figures in literature and the visual arts.

Haq, S. and Girotto, S., (2003) Abillity and Intelligibility, Wayfinding and environmental, proceedings of the 4th International space syntax symposium, London, England.

Heidegger, M. (1996). Being and time: a translation of sein und zeit (J. Stambaugh trans.). Albany: State University of New York Press.

Hernández, F. (2010). Bhabha for Architects

Hillier, B. (2007). Space is the machine: a configurational theory of architecture. London: Space Syntax Laboratory.

Huddart D (2018). Homi K. Bhabha. Oxford Bibliographies. Retrieved December 30, 2020, from: https://www.oxfordbibliographies.com/view/document/obo-9780190221911/obo-97801902219110057.xml

Huyssen, A. (1995). Twilight Memories: Marking time in a Culture of Amnesia. Routledge: London.

ICOMOS, 2013. The Burra Charter, Austria: Burwood.

Jagannath T, (2018). Edward Soja's Theories of Urban Space

Jencks, Charles. (1993). Architecture Today. Academy Editions, London.

Kohler, N. and Hassler, U. (2002), "The building stock as a research object", Building Research \& Information, Vol. 30 No. 4, pp. 226-36.

Kincaid, David. (2002). Adapting Buildings for Changing Uses Guidelines for Change of Use Refurbishment. First Ed, Spon Press, London.

Lee, Michael Soon. (2018). https://www.ethnoconnect.com/articles/1-what-is-cultural-diversity

Lefebvre, H. (1991). The production of space (D. Nicholson-Smith). Cambridge: Blackwell.

Loveday T. (2008). Construction, the Third Space of Architecture. Society of Architectural Historians of Australia and New Zealand Conference 2008

Low, S. M., \& Smith, N. (Eds.). (2006). Introduction: The Imperative of Public Space, in the politics of public space. New York: Routledge.

Lukacs, J. (1970). The Bourgeois Interior, American Scholar 39, no. 4: 620-621. 
Miles \& Huberman. (1994). Qualitative Data Analysis (Thousand Oaks, CA: SAGE, 1994); Zina O'Leary, The Essential Guide to Doing Your Research Project (Thousand Oaks, CA: SAGE, 2010).

Nissen, y. (2008). Urban Transformation: From Public and Private Space to Spaces of Hybrid Character. Sociologicky časopis/Czech Sociological Review, Vol. 44, No. 6, pp. 1129-1149.

Nora, P. (1989). Between Memory and History: Les Lieux de Mémoire, in Representations: Special Issue: Memory and Counter-Memory, No. 26, Spring 1989. University of California, Press: Berkeley: pp.7 - 24.

Peterson, K. H., and Rutherford, A. (2006). Fossil Psyche, in the post colonial studies reader, B. Ashcroft et al (eds). Routledge: New York: $139-142$.

Pluta, Katarzyna. (2016). Public hybrid spaces as a component of contemporary cities. A: Virtual City and Territory. "Back to the Sense of the City: International Monograph Book". Barcelona: Centre de Política de Sòl i Valoracions. p. 157-172

Ridhika Naidoo. (2009). Maya Lin: museum of chinese in america opens september 22. Retrieved December 24, 2020, from: https://www.designboom.com/architecture/maya-lin-museum-of-chinese-in-americaopens-september-22/

Sargın G, Savas A, (2011) Dialectical urbanism: Tactical instruments in urban design education

Schulz, Norberg C. (1971). Existence, space and architecture. New York: Praeger.

Sennett, R. (2008). Capitalism and the City: Globalization, Flexibility, and Indifference. In Cities of Europe: Changing Contexts, Local Arrangements, and the Challenge to Urban Cohesion (pp. 109-122). Blackwell Publishing Ltd.

Steeds, L. (2014). Flexible Workspaces for Flexible Workers. Retrieved December 24, 2018, from http://popupcity.net/flexible-workspaces-for-flexible-workers/

The Dreaming Wall. Collective Buzz in Town. - Conceptual Devices. (n.d.). Retrieved December 28, 2018, from http://www.conceptualdevices.com/2009/01/dreaming-wall.

Undertaking Acquisition: Chronicles of our Time. (n.d.). Retrieved December 28, 2018, from https://www.christinelieu.com/room-202-archival-library-of-found-treasures/.

YZ Works, Manchester's newest hybrid co-workspace to launch in August - Invest in Manchester. (n.d.). Retrieved December24, 2018, from https://www.investinmanchester.com/latest-news/2017/7/12/xyzworks-manchesters-newest-hybrid-co-work-space-to-launch-in-august-a2494

Zecc Architecten|Studio Heldergroen Haarlem. (n.d.). Retrieved December 24, 2018, from https://www.arthitectural.com/zecc-architecten-studio-heldergroen-haarlem/

\section{Resume}

Eman Al-Braifkani holds a master's degree in interior architecture at Eastern Mediterranean University (EMU) in N. Cyprus, 2019. She has authored a book on history of interior design and number of research papers in the field of architecture and interior design. Her research interests include issues of architecture philosophy and interior spaces, sustainability, and hospitality design. She is a member of the Iraqi Engineers Syndicate / Architectural Engineering since 2003.

Kagan Gunce is Professor of Interior Architecture at Eastern Mediterranean University (EMU) in N. Cyprus. He also serves as Vice Chair of the Institute of Graduate Studies and Research at EMU. He holds bachelor's degree, master's and PhD degrees in Architecture from EMU. His research interests include architectural \& interior architectural spaces issues, environmental psychology, architectural theory, conservation of industrial heritage and traditional housing. 